\title{
A peer evaluation of the community-based education programme for medical students at the University of Zimbabwe College of
}

\section{Health Sciences: A southern African Medical Education Partnership} Initiative (MEPI) collaboration

D Michaels, ${ }^{1}$ BSocSc, MPhil (Maternal and Child Health), MSc (Epidemiology), PhD; I Couper, ${ }^{2}$ MB BCh, MFamMed; M S Mogodi, ${ }^{3}$ MB ChB, MPH; J G Hakim, ${ }^{4}$ MB ChB, MMed (Internal Medicine), MMedSci (Clinical Epidemiology); Z Talib, ${ }^{5}$ MD (Internal Medicine); M H Mipando, ${ }^{6}$ BEd, MSc; M M Chidzonga, ${ }^{4}$ BDS, FFDRCSI, MMedSci (Clinical Epidemiology), PGD IntResEthics; A Matsika, ${ }^{4}$ BBS, MBA; M Simuyemba,${ }^{7}$ BSc, MB ChB, MPH

${ }^{1}$ School of Public Health, Faculty of Health Sciences, University of Cape Town, South Africa

${ }^{2}$ Ukwanda Centre for Rural Health, Faculty of Medicine and Health Sciences, Stellenbosch University, Cape Town, South Africa

${ }^{3}$ Faculty of Medicine, University of Botswana, Gaborone, Botswana

${ }^{4}$ University of Zimbabwe College of Health Sciences, Harare, Zimbabwe

${ }^{5}$ Medical Education Partnership Initiative (MEPI) Co-ordinating Centre, George Washington University, Washington DC, USA

${ }^{6}$ College of Medicine, University of Malawi, Blantyre, Malawi

${ }^{7}$ Medical Education Partnership Initiative (MEPI), University of Zambia, Lusaka, Zambia

Corresponding author: D Michaels (desireclas@gmail.com)

Background. The University of Zimbabwe College of Health Sciences (UZCHS), Harare, which has a long tradition of community-based education (CBE), has not been evaluated since 1991. An innovative approach was used to evaluate the programme during 2015.

Objectives. To evaluate the CBE programme, using a peer-review model of evaluation and simultaneously introducing and orientating participating colleagues from other medical schools in southern Africa to this review process.

Methods. An international team of medical educators, convened through the Medical Education Partnership Initiative, worked collaboratively to modify an existing peer-review assessment method. Data collection took the form of pre-visit surveys, on-site and field-visit interviews with key informants, a review of supporting documentation and a post-review visit.

Results. All 5 years of the medical education curriculum at UZCHS included some form of CBE that ranged from community exposure in the 1st year to district hospital-based clinical rotations during the clinical years. Several strengths, including the diversity of community-based activities and the availability of a large teaching platform, were identified. However, despite the expression of satisfaction with the programme, the majority of students indicated that they do not plan to work in rural areas in Zimbabwe. Several key recommendations were offered, central to which was strengthening the academic co-ordination of the programme and curriculum renewal in the context of the overall $\mathrm{MB}$ ChB curriculum.

Conclusion. This evaluation demonstrated the value of peer review to bring a multidimensional, objective assessment to a CBE programme.

Afr J Health Professions Educ 2017;9(3):138-143. DOI:10.7196/AJHPE.2017.v9i3.733

The Medical Education Partnership Initiative (MEPI) was a large-scale, US government investment in strengthening the health workforce in Africa by providing medical schools with funding to implement activities based on local needs and priorities. Schools that were awarded the grant chose to invest in strengthening community-based education (CBE) and formed a technical working group convened by the Coordinating Centre of MEPI (a partnership of institutions also funded by the MEPI grant). The technical working group collaborated with CapacityPlus (a US Agency for International Development (USAID)-supported programme with funding specifically allocated to work with the MEPI schools) to strengthen their CBE programmes. ${ }^{[1]}$ Within this context, the University of Zimbabwe College of Health Sciences (UZCHS) requested a peer review of its CBE programme. The evaluation served as a learning exercise for both UZCHS and other medical schools in the MEPI network in applying the peer-review process while evaluating the UZCHS CBE programme.
CBE is increasingly included as part of health sciences curricula across the globe. It forms part of an educational strategy to address the worldwide inequities in human resources for health by preparing graduates for service to rural and under-served populations. ${ }^{[2]}$ The protocol developed by the Collaboration for Health Equity through Education and Research (CHEER) was adapted for use by UZCHS to evaluate its CBE programme. CHEER was formed in South Africa (SA) during 2003 to examine strategies that would increase the likelihood of health professional graduates choosing to practise in rural and under-served areas. ${ }^{[3,4]}$ Since then, the CHEER model has demonstrated effectiveness in examining complex outcomes in medical education in countries other than SA, as reported by S Reid on the University of Cape Town's Primary Health Care Directorate website (www. primaryhealthcare.uct.ac.za/).

The medical school in Harare, Zimbabwe was established in 1963 and runs a 5 -year undergraduate medical programme ( $\mathrm{MB} \mathrm{ChB})$. The uni- 
versity's intention to expose students to CBE originated with the idea of a 'village family scheme', whereby students were attached to families in rural areas ${ }^{[5]}$ The evaluated format of the CBE programme was formally launched in 1987. At the time of the peer review, 22 academic departments and 67 clinical teaching sites contributed to the implementation of the programme.

\section{Objective}

The aim of the review was to train colleagues from the network of MEPI schools in using the CHEER approach (Fig. 1) and to conduct an evaluation of how the medical school's CBE programme served to encourage future rural practice. The specific objectives were: $(i)$ to identify gaps between theory and practice in education and training; (ii) to provide a report for ongoing curricular review; and (iii) to share best practices regarding preparation of students for practice in rural and under-served areas.

\section{Methods}

A descriptive study design, using mainly qualitative methods that focused primarily on semi-structured interviews and review of supporting documentation, was employed. In addition, a pre-visit questionnaire was distributed to faculty and students for completion from September to December 2014 to serve as baseline data prior to the review visit. All respondents for pre-visit questionnaires were identified by representatives of UZCHS using convenience sampling, whereby as many students and appropriate staff as were available were invited to complete the forms. Purposive sampling was done for the on-site face-to-face interviews in February 2015 through the identification of appropriate key faculty members and students, as well as graduates and clinical preceptors at two district hospitals. During the visit, an initial presentation of the findings and recommendations was made to the faculty to corroborate and supplement the findings. A follow-up visit to present final key findings and recommendations was conducted during May 2015; this meeting was also used to further validate the findings prior to drafting a final written report.

Two facilitators from SA (IC and DM), who were experienced in the CHEER peer-review approach, led a team of representatives from the medical schools in Botswana, Zambia and Malawi, who served as peer reviewers while being orientated to the evaluation process. Representatives of UZCHS were involved in the process, which commenced $\sim 7$ months prior to the visit and involved protocol adaptation and questionnaire distribution.

During the visit in February 2015, the reviewers divided into two subteams and conducted interviews of $\sim 1$ hour. Written notes were taken during the interviews, which were conducted with individual faculty members or pairs from the same department. Written, informed consent was obtained from each interviewee prior to commencement of the interview.

Students presented in two large groups of $\sim 50$ students each. Each group was seen separately but in parallel. Due to the large numbers of students, a paper response method was used to encourage response, whereby each student was handed a slip of paper on which to write their answer. Following each response, the paper was handed in and a brief discussion ensued to identify common issues.

\section{Analysis}

Analysis of pre-visit staff questionnaires was done using a grid to summarise answers to the questions as a result of a paucity of responses. The responses to the pre-visit student questionnaires were captured at UZCHS using the REDCap (USA) database. The descriptive analysis was conducted by members of the peer-review team in SA, with online access to the database. Thematic analysis was conducted on the qualitative aspects of the survey.

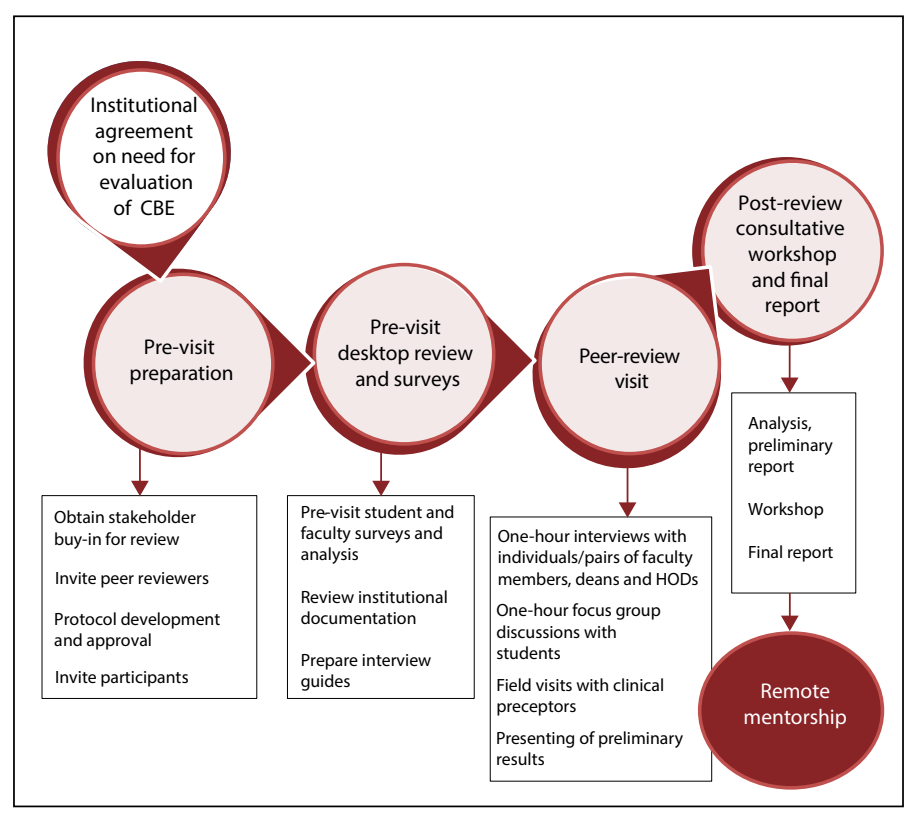

Fig. 1. The Collaboration for Health Equity through Education and Research (CHEER) peer-review process at the University of Zimbabwe College of Health Sciences. $(C B E=$ community-based education; HODs = heads of department. $)$

All data from on-site interviews were analysed using recursive abstraction and summarised along broad themes outlined in the interview schedule based on the CHEER evaluation framework (Table 1), including the nature of involvement of each department in CBE (Table 2). The results were discussed by the review team, with consensus being reached on themes within and across the interviews. The students' paper responses to the structured questions were analysed using a thematic approach.

Research ethical approval was granted by the Medical Research Council of Zimbabwe (MRCZ) on 9 June 2014 (ref. no. MRCZ/A/1841).

\section{Results}

The CBE programme at UZCHS was found to be constrained by a number of remote and recent pressures, including the financial crisis in Zimbabwe, increasing staff shortages, increased student numbers, and deteriorating infrastructure. Despite these pressures, which had evolved over time, the programme had expanded from 10 purpose-built sites in eight provinces to more than 60 sites across all provinces, with positive relationships between the university, the Ministry of Health and Child Care, mission hospitals and private medical care providers in the mining industry.

\section{Pre-visit survey results}

The pre-visit surveys conducted from November to December 2014 resulted in a low response rate, with 5\% $(n=54 / 1164)$ and $26 \%(n=5 / 19)$ of students and faculty responding, respectively. Key findings from the student survey were as follows: the majority (94\%) did not plan to practise in rural or underserved areas upon graduation; community health workers were perceived as the most significant 'teachers' not employed by the university; and half of the respondents were in contact with graduates. The low response from faculty resulted in inadequate baseline data being available to reviewers. Faculty respondents were mainly involved with the clinical years (years 3 - 5), and none reported being involved in the CBE programme. All indicated that there was no policy that specified student recruitment from rural or underserved areas. 


\section{Research}

Table 1. Adapted CHEER evaluation framework

\begin{tabular}{|c|c|c|c|c|}
\hline \multirow[b]{2}{*}{$\begin{array}{l}\text { Criterion } \\
\text { number }\end{array}$} & \multirow[b]{2}{*}{ Evaluation criteria } & \multicolumn{3}{|c|}{ Score } \\
\hline & & Less than expected & Adequate & Better than expected \\
\hline \multirow[t]{2}{*}{1} & $\begin{array}{l}\text { Faculty mission } \\
\text { statement }\end{array}$ & $\mathrm{R} / \mathrm{U}$ not mentioned ${ }^{*}$ & $\begin{array}{l}\text { Some mention or indirect } \\
\text { reference }\end{array}$ & Explicitly supportive \\
\hline & & \multicolumn{3}{|c|}{$\begin{array}{l}\text { Stated: 'Community-orientated and community-driven training and learning' } \\
\text { Issue of social accountability - where graduates go not addressed }\end{array}$} \\
\hline \multirow[t]{2}{*}{2} & Resource allocation & None $^{\dagger}$ & $\begin{array}{l}\text { Some staff and funding, but not } \\
\text { enough }^{*}\end{array}$ & $\begin{array}{l}\text { Sufficient staff and funding for } \\
\text { sustainability }\end{array}$ \\
\hline & & \multicolumn{3}{|c|}{ Biggest constraint. Worked well with external funding. The financial crisis had a major negative effect ${ }^{\dagger}$} \\
\hline \multirow[t]{2}{*}{3} & Student selection & No policy with regard to $\mathrm{R} / \mathrm{U}^{*}$ & Some policy with regard to $\mathrm{R} / \mathrm{U}$ & $>25 \%$ rural origin \\
\hline & & \multicolumn{3}{|c|}{$\begin{array}{l}\text { None }^{\dagger} \\
\text { Reported that most students come from lower SES backgrounds }{ }^{\dagger}\end{array}$} \\
\hline \multirow[t]{2}{*}{4} & First exposure & Final year, if at all & Middle years & 1st year* \\
\hline & & \multicolumn{3}{|c|}{$\begin{array}{l}\text { Behavioural sciences convene } 1 \text { st-year exposure }{ }^{\dagger} \\
\text { Exposure in every subsequent year }{ }^{\dagger}\end{array}$} \\
\hline \multirow[t]{2}{*}{5} & Length of exposure & None $^{\dagger}$ & $<5 \% *$ & $>25 \%$ of practical in $\mathrm{R} / \mathrm{U}$ areas \\
\hline & & \multicolumn{3}{|c|}{$4-8$ weeks/year ( $1-5$ days/week for the duration of attachment $)^{\dagger}$} \\
\hline \multirow[t]{2}{*}{6} & Practical experience & $\mathrm{None}^{\dagger}$ & $\begin{array}{l}\text { Students watch and listen to } \\
\text { others }\end{array}$ & $\begin{array}{l}\text { Students hands-on and } \\
\text { contributing }^{*}\end{array}$ \\
\hline & & \multicolumn{3}{|c|}{ Develops over the years; 5 th year very hands-on ${ }^{\dagger}$} \\
\hline \multirow[t]{2}{*}{7} & Theoretical input & $\mathrm{None}^{\dagger}$ & $\mathrm{R} / \mathrm{U}$ mentioned ${ }^{*}$ & Critical reflection on $\mathrm{R} / \mathrm{U}$ issues \\
\hline & & \multicolumn{3}{|c|}{ Mainly in community medicine; some reference in other disciplines ${ }^{\dagger}$} \\
\hline \multirow[t]{2}{*}{8} & $\begin{array}{l}\text { Involvement with } \\
\text { community }\end{array}$ & Tourism-type exposure* & Engagement or intervention & Ongoing joint reflection \\
\hline & & \multicolumn{3}{|c|}{ Learn from the community, but don’t contribute to it; unlike the rehabilitation sciences students ${ }^{\dagger}$} \\
\hline \multirow[t]{2}{*}{9} & $\begin{array}{l}\text { Relationship with } \\
\text { health service }\end{array}$ & Students are a drain/burden & Students are tolerated & $\begin{array}{l}\text { Students' input is welcomed and } \\
\text { used }^{*}\end{array}$ \\
\hline & & \multicolumn{3}{|c|}{ Very positive (especially senior years) $^{\dagger}$} \\
\hline \multirow[t]{2}{*}{10} & Assessment of students & $\begin{array}{l}\text { No formal assessment for rural } \\
\text { learning }\end{array}$ & $\begin{array}{l}\text { Assessment was done, but not } \\
\text { pass/fail }\end{array}$ & $\begin{array}{l}\text { Pass/fail contribution from rural } \\
\text { component }\end{array}$ \\
\hline & & \multicolumn{3}{|c|}{ Reports and presentations compulsory, but no rigorous assessment of knowledge and skills acquired during $\mathrm{CBE}^{\dagger}$} \\
\hline \multirow[t]{2}{*}{11} & $\begin{array}{l}\text { Research and } \\
\text { programme evaluation }\end{array}$ & $\begin{array}{l}\text { No programme evaluation or } \\
\text { reflection* }\end{array}$ & $\begin{array}{l}\text { Evaluation is done, but not } \\
\text { specific to } \mathrm{R} / \mathrm{U}\end{array}$ & $\begin{array}{l}\text { Current educational research with } \\
\text { regard to } \mathrm{R} / \mathrm{U}\end{array}$ \\
\hline & & None $^{\dagger}$ & & \\
\hline \multirow[t]{2}{*}{12} & $\begin{array}{l}\text { Programme oversight } \\
\text { and co-ordination }\end{array}$ & $\begin{array}{l}\text { No academic co-ordination; } \\
\text { administrative co-ordination } \\
\text { only* }\end{array}$ & $\begin{array}{l}\text { Some academic oversight at } \\
\text { departmental level; some academic } \\
\text { co-ordination }\end{array}$ & $\begin{array}{l}\text { Good co-ordination with senior- } \\
\text { level support and academic } \\
\text { oversight }\end{array}$ \\
\hline & & \multicolumn{3}{|c|}{ There was good administrative co-ordination from the dean's office ${ }^{\dagger}$} \\
\hline
\end{tabular}

\section{Review visit results}

Face-to-face interviews were conducted with the dean, 23 faculty members in preclinical and clinical departments, four recent graduates and two off-site clinical preceptors. Modified group interviews were conducted with 3rd-year $(n=69)$ and 4th-year $(n=52)$ students. Several strengths and challenges were identified using the CHEER evaluation framework, as illustrated in Table 1.

The faculty mission statement does not overtly mention rural and under-served populations, but states that the institution strives for 'community oriented and community driven training and learning. The length of exposure to field attachments was estimated to be $~ 5 \%$ per year on average, with time spent ranging between 1 and 5 days per week for 4 - 8 weeks within one study year (Table 2 ). The community medicine curriculum provides theoretical input regarding healthcare in rural or under-served areas. Staff who supervise the preclinical and clinical field attachments are mostly non-clinicians and often work under difficult circumstances; yet, the programme boasts a large teaching platform (in excess of 67 sites across all provinces and districts in Zimbabwe), providing various exposure options. 
Table 2. Summary of student exposure to community-based education

\begin{tabular}{lllll}
\hline Year & Site & Duration & Department & Focus \\
\hline 1 & Epworth (peri-urban) & Fridays: $2 \times 8$ weeks & Behavioural sciences (psychiatry) & $\begin{array}{l}\text { Health-seeking behaviour; family } \\
\text { health study }\end{array}$ \\
2 & $\begin{array}{l}\text { Communities around district } \\
\text { sites: variable numbers }\end{array}$ & 4-week block & $\begin{array}{l}\text { Community medicine focus; all } \\
\text { departments involved }\end{array}$ & $\begin{array}{l}\text { Community characteristics, needs } \\
\text { and structure }\end{array}$ \\
& $\begin{array}{l}\text { District hospitals in various } \\
\text { towns }\end{array}$ & 4-week block & $\begin{array}{l}\text { 'Field attachment office' (deanery); } \\
\text { all departments involved }\end{array}$ & $\begin{array}{l}\text { The health system; clinical skills } \\
\text { (ward rounds, patient clerking) }\end{array}$ \\
& Urban clinics & 4-week practicum & Community medicine & $\begin{array}{l}\text { Maternal and child health focus; } \\
\text { general primary care medicine }\end{array}$ \\
& District hospitals in various & 4-week block & 'Field attachment office' (deanery); & $\begin{array}{l}\text { Core clinical disciplines; audit (ward } \\
\text { rounds, patient clerking and ongoing } \\
\text { atlient management) }\end{array}$
\end{tabular}

Table 3. Key recommendations

\begin{tabular}{|c|c|}
\hline $\begin{array}{l}\text { Key recommendations } \\
\text { (presented) }\end{array}$ & Key recommendations (adopted) \\
\hline $\begin{array}{l}\text { Identify academic co-ordinator } \\
\text { for } \mathrm{CBE}\end{array}$ & $\begin{array}{l}\text { Identify academic management } \\
\text { structure for CBE } \\
\text { Monitoring and evaluation }\end{array}$ \\
\hline $\begin{array}{l}\text { Revise CBE programme based on } \\
\text { review results }\end{array}$ & $\begin{array}{l}\text { Revise field attachment } \\
\text { programme }{ }^{\star} \text { to evolve into CBE } \\
\text { based on results of review }\end{array}$ \\
\hline $\begin{array}{l}\text { Integrate CBE programme across } \\
\text { medical departments }\end{array}$ & $\begin{array}{l}\text { Integrate the } \mathrm{MB} \text { ChB } \mathrm{CBE} \\
\text { programme across all teaching } \\
\text { departments }\end{array}$ \\
\hline $\begin{array}{l}\text { Align learning objectives with the } \\
\text { overall medical curriculum }\end{array}$ & $\begin{array}{l}\text { Align CBE learning objectives with } \\
\text { the overall medical curriculum }\end{array}$ \\
\hline \multicolumn{2}{|l|}{$\begin{array}{l}\text { Launch a parallel medical } \\
\text { curriculum revision process }\end{array}$} \\
\hline $\begin{array}{l}\text { Align teaching platform to } \\
\text { learning outcomes }\end{array}$ & $\begin{array}{l}\text { Align teaching platform to } \\
\text { learning outcomes }\end{array}$ \\
\hline $\begin{array}{l}\text { Increase } \mathrm{CBE} \text { exposure time } \\
\text { across the years }\end{array}$ & $\begin{array}{l}\text { Increase CBE exposure time } \\
\text { across the years }\end{array}$ \\
\hline Improve student supervision & Improve student supervision \\
\hline $\begin{array}{l}\text { Attend to student accommodation, } \\
\text { transport, maintenance and } \\
\text { resources issues }\end{array}$ & $\begin{array}{l}\text { Attend to student accommodation, } \\
\text { transport, maintenance and } \\
\text { resources issues }\end{array}$ \\
\hline \multicolumn{2}{|c|}{$\mathrm{CBE}=$ community-based education } \\
\hline \multicolumn{2}{|c|}{$\begin{array}{l}\text { *University of Zimbabwe College of Health Sciences referred to existing CBE activities as the field } \\
\text { attachment programme. }\end{array}$} \\
\hline \multicolumn{2}{|c|}{$\begin{array}{l}\text { Note: The column on the left indicates recommendations made by the peer-review team, while } \\
\text { the column on the right indicates the consensus reached by the university representatives, } \\
\text { including the dean. }\end{array}$} \\
\hline
\end{tabular}

\section{Strengths}

There are a number of areas where UZCHS performed better than expected using the peer-review tool: early exposure to rural and under-served communities occurs from the 1st year onwards; CBE occurs in every year of study; practical experience is afforded to students during community-based activities (although the extent depends on their year of study, with more senior students having more 'hands-on' clinical experience); and a good relationship with health service personnel and the ministry of health.

The establishment of a Health Professions Education Department in 2014 was intended to encourage and facilitate the training of clinicians and other academics in educational approaches and skills.
Table 4. Post-review visit: Key outcomes

- The establishment of a working committee for CBE revision. The first meeting of the committee was planned for 2 weeks from the date of the post-review meeting. The dean called the meeting and confirmed the convenor of the committee.

- The appointment of a convenor of this working group, who was nominated by the dean (the head of the HPE Unit).

- The inclusion of CBE in the staff development programme originally planned to focus on MB ChB curriculum planning.

- The agreement that the $\mathrm{CBE}$ curriculum review would take place in the context of the overall $\mathrm{MB} \mathrm{ChB}$ curriculum revision.

- The agreement that student supervision will be revised and improved to include an academic component. The HPE Unit will develop an orientation programme for all supervisors to support the strengthening of CBE. This orientation will include a revision of the guidelines for supervision as per the new goals set for competencies that students should achieve during the field attachment.

- The agreement that HEALZ graduates from UZCHS would be co-opted to assist the HPE Unit and the CBE curriculum committee with the curriculum revision of the CBE programme.

- It was agreed that UZCHS will explore the implementation of innovative funding strategies for the CBE programme.

$\mathrm{CBE}=$ community-based education; $\mathrm{HPE}=$ health professions education; $\mathrm{UZCH}=$ University of Sciences: $\mathrm{HEAIZ}=$ Health Education and Advanced Leadership for Zimbabwe.

Accommodation at two field sites was upgraded in 2014/2015 and internet facilities were expanded, including a repository for textbooks and assignments.

Students value and enjoy the CBE experience, despite the poor living conditions at some sites due to lack of adequate maintenance, oversight and funding. They reported that the experiences impacted positively on their personal growth, empathic skills and professionalism.

\section{Challenges}

A number of limitations and challenges emerged. The institutional oversight and investment was limited, evidenced by the last $\mathrm{MB} \mathrm{ChB}$ curriculum having been reviewed in the 1980s and the last substantial amendments to the field attachment programme made in the 1990s. The relationship between the medical school and the community leans towards a 'tourismtype' exposure, with no evidence of a partnership with the community, especially during the non-clinical years.

The dean has provided high-level support and visibility for the programme and administrative oversight for the 2nd-, 3rd- and 5th-year 
CBE programmes, but the transfer of the programme to his office appears to have created a gap in the day-to-day academic oversight and co-ordination of the programme. Faculty and students report 'silo' learning or a lack of integration between disciplines, and perceive a disconnect between the objectives of the CBE programme and the overall $\mathrm{MB} \mathrm{ChB}$ curriculum. Supervisors and clinical preceptors reported a poor understanding of the specific objectives of the CBE programme, particularly in the clinical years, as well as dissatisfaction with some of the infrastructure, support materials and resources available to implement the programme. Students reported inadequate supervision from medical professionals during communitybased activities

The various teaching departments reported that they do not have any overt teaching and learning outcomes for the CBE placement, and while there is some assessment of students' $\mathrm{CBE}$ experience in the form of reports and presentations and during the behavioural sciences course examinations in the 1st year, it is not rigorously assessed throughout the study years. Clinical skills proficiency was identified by preceptors as a major gap in students' capacity during field placements. Senior students reported that they were not adequately prepared to practise in rural areas, which lacked adequate nearby referral networks and required them to perform clinical skills they were not comfortable with. Despite their generally positive CBE experiences, most students reported that they have no intention of practising in rural or under-served areas when they qualify.

\section{Key recommendations for UZCHS}

The recommendations presented by the review team were generally well received and feasible, with some modifications (Table 3). The central recommendation was that UZCHS needed to strengthen the structures for curriculum review and academic co-ordination of the CBE programme and assign a person or group to the academic co-ordination of the programme. Other key recommendations included: (i) to convert the current 'field attachment' into a formal CBE programme, ensuring that there is a spiral of learning that links CBE activities from one year to the next with increasing levels of competency; (ii) to align learning objectives of the CBE programme with the overall medical curriculum, leveraging international guidelines, such as the Global Consensus on the Social Accountability of Medical Schools ${ }^{[6]}$ the Lancet Commission Report, ${ }^{[7]}$ the World Health Organization's Transformation of Health Professions Education, 2013, ${ }^{[8]}$ and the approach of evidence-based medical education; ${ }^{[9,10]}$ (iii) to improve student supervision and set clear learning objectives and outcomes, thereby integrating knowledge across disciplines and ensuring skills proficiency; and (iv) to consider the introduction of family medicine to strengthen the provision of primary care, while postgraduate trainees in family medicine could potentially provide supervisory support to undergraduate students during CBE placements.

Other recommendations included reviewing the existing teaching sites to ensure they each provide appropriate learning opportunities, strengthening inter-professional learning through the CBE experience and improving the infrastructure (of accommodation and the health facilities), recognising that the latter will require political will and innovative income-generating strategies.

\section{Post-review visit results}

A 2-day meeting reviewing the recommendations with the dean, heads of department, and key faculty led to several main decisions and plans for improvement of the CBE programme (Table 4). One of the key decisions, taken in the absence of available funding for an academic co-ordinator, was to convene a working committee chaired by the head of the Health Professions Education Department to provide academic oversight of the
CBE programme. Remote support was provided to the institution by the review team to facilitate implementation of adopted recommendations.

\section{Discussion}

Peer review is not an accreditation process but rather focuses on providing health sciences schools with organising principles and an opportunity to reflect on the institutional standards and curriculum, which will help them become more accountable in addressing some of the health inequities and improvements to the health system.

The process of the review supported peer reviewers to learn from each other and share their experiences, similar to the in-country consortia of medical schools that formed within the MEPI network. ${ }^{[11}$ Medical schools in the region share common constraints of limited resources and infrastructure ${ }^{[12,13]}$ and many face the challenge of finding funding for objective programme evaluations. The peer-review approach therefore affords a cost-effective mechanism to provide valuable feedback.

The post-visit support was a modification of the CHEER model and may well be a feature that others can incorporate in the future.

\section{Common challenges shared with other MEPI schools}

UZCHS has several challenges in common with other MEPI partners regarding the $\mathrm{CBE}$ programme, such as inadequate clinical preceptorship at CBE sites, increasing admission numbers and limitations of infrastructure and logistics, which include inadequate internet connectivity for online technology expansion, accommodation and transport. ${ }^{[1]}$ Other key areas needing attention relate to the $\mathrm{CBE}$ curriculum, appropriate course materials, textbook availability and alignment with the central curriculum. These challenges may undermine a major aim of CBE, which seeks to expose students to rural and under-served communities with the objective of encouraging future practice in these areas. Despite the positive sentiments expressed about the CBE experience, most students at UZCHS would not choose to practise in rural areas in future. This does not bode well for Zimbabwe, considering that the majority of the population (67\%) live in rural areas and are dependent on government health services. ${ }^{[14]}$ This finding contradicts previous findings that the exposure to CBE in medical curricula increases the likelihood of graduates choosing to work in rural and under-served areas. ${ }^{[1,15]}$ Perhaps it is not just exposure to CBE (which in practice spans each year at UZCHS), but the quality and nature of that exposure which impacts positively on graduate choice. Studies have shown that three main factors influence choice of rural practice by medical graduates, i.e.: (i) rural origin; (ii) positive clinical and educational experience in rural placements during undergraduate medical training; and (iii) targeted postgraduate training for rural practice. ${ }^{[16,17]}$ There is no explicit student recruitment and selection policy aimed at students from rural origin at UZCHS, with the majority reporting being of urban origin, and no postgraduate rural training is offered. Therefore, all three factors may be linked to graduate choices at UZCHS.

\section{Key lessons}

While the on-site review occurs within a relatively short space of time (3 - 5 days), the entire process takes several months. ${ }^{[18]}$ Hosts and reviewers must therefore be committed to participation throughout the entire process. Buy-in from key stakeholders is important to gather meaningful information and to implement recommendations.

The purpose of evaluation is to identify whether a programme meets its objectives. Without clearly articulated programme goals, evaluation is challenging. 
A specific area of focus for the review is important, as there is a danger of covering too much (depth $\mathrm{v}$. breadth).

External peers can offer safe, empowering and multifaceted support to improve and evolve educational programmes within institutions, while enjoying a mutual learning experience. Peer review is a fluid process and the approach is one of a conversation with supportive peers, with openness to adaptation. The protocol should, therefore, not be rigidly adhered to if it is not effective in a particular context. In this instance, the addition of the 12th criterion to the evaluation framework was deemed an important adaptation for the UZCHS context, and probably also for other CBE programmes.

\section{Study limitations}

Data collection of pre-review-supporting documentation and completion of course curriculum spreadsheets was unsuccessful owing to the very poor response from faculty. This led to interviews being focused mainly on gathering general information without adequate time for in-depth probing.

Daily debriefing sessions of the reviewer team with the host institution's academic representatives would have been very helpful in clarifying issues as they arose. Incorporating such meetings into the daily schedule would be best.

Only two community-based sites were selected because of their proximity to the university. Thus, the reviewers relied on the two preceptors to relate their experiences and perceptions rather than gaining first-hand information and observations beyond the two sites visited.

\section{Conclusion}

This evaluation demonstrated the value of a peer-review process to offer a multidimensional, external but friendly assessment of a CBE programme. The process provided valuable insight and triggered institutional commitment and motivation to revise and align the curriculum with the intended goals. Regular evaluation of CBE activities is critical to ensure that educational goals are being met and that limited resources for medical education are being used effectively to train a relevant workforce.

Acknowledgements. We wish to acknowledge Ms Rebecca Bailey and the CapacityPlus team at IntraHealth International, who supported the planning and co-ordination of the peer-review visit and were part of the initial conceptualisation of the project. We thank the staff, students and clinical preceptors of the University of Zimbabwe for their participation in the peerreview process.

Author contributions. DM: co-facilitated the peer-review project, contributed to the analysis, conducted the write-up of the project results and wrote the manuscript. IC: facilitated the peer-review project, was involved in the concept and design of the process, contributed to the data analysis and made substantial critical revisions to all drafts of the manuscript. MSM: peer reviewed the project, contributed to the data analysis and made critical revisions of the manuscript. JGH: principal investigator on the UZCHS MEPI project, and involved in the conception and design of the process, as well as critical evaluation of the draft manuscript. ZT: member of the project management team and made substantial contributions to the interpretation of the data, as well as editorial revision of the manuscript. MHM: peer reviewed the project, and contributed to the data analysis and critical evaluation of the draft manuscript. MMC: principal investigator of the project, involved in its conception and design, as well as in critical evaluation of the draft manuscript. AM: on-site project co-ordinator and responsible for pre-visit data collection, as well as contributing to the review of the manuscript. MS: peer reviewed the project, and contributed to the data analysis and critical evaluation of the manuscript. All authors approved the final submitted version of the article.

Funding. Funding was received from the CapacityPlus project within IntraHealth International.

Conflicts of interest. None.

1. Mariam DH, Sagay AS, Arubaku W, et al. Community-based education programs in Africa: Faculty experience within the Medical Education Partnership Initiative (MEPI) network. Acad Med 2014;89(8):S50-S54. https://doi org/10.1097/ACM.0000000000000330

2. Chen L, Evans T, Anand S, et al. Human resources for health: Overcoming the crisis. Lancet 2004;364(9449):19841990. https://doi.org/10.1016/S0140-6736(04)17482-5

3. Reid S, Cakwe M; on behalf of Collaboration for Health Equity through Education and Research (CHEER). The contribution of South African curricula to prepare health professionals for working in rural or underserved areas in South Africa: A peer review evaluation. S Afr Med J 2011;101(1):34-38. https://doi.org/10.7196 SAMJ.4526

4. Michaels DC, Reid SJ, Naidu CS. Peer review for social accountability of health sciences education: A model from South Africa. Educ Health 2014;27(2):127. https://doi.org/10.4103/1357-6283.143728

5. Tsikirayi $\mathrm{CMR}$ Todd $\mathrm{CH}$. Commity-based medical education and curriculum change: The field attachment Tsikirayi CMR, Tode 6rograme of ability.org/ (accessed 26 July 2017).

. Frenk J, Chen L, Bhutta ZA, et al. Health professionals for a new century: Transforming education to strengthen health systems in an interdependent world. Lancet 2010;376(9756):1923-1958. https://doi.org/10.1016/S01406736(10)61854-5

8. Couper I, Sen Gupta T, McInerney P, Larkins S, Evans R. Transforming and scaling up health professional education and training: Policy brief on faculty development. http://whoeducationguidelines.org./sites/default/ files/uploads/whoeduguidelines_PolicyBrief_FacultyDevelopment.pdf (accessed 26 July 2017).

9. Mayer RE. Applying the science of learning to medical education. Med Educ 2010;44(6):543-549. https://do org/10.1111/j.1365-2923.2010.03624.x

10. Levinson AJ. Where is evidence-based instructional design in medical education curriculum development? Med Educ 2010;44(6):536-537. https://doi.org/10.1111/j.1365-2923.2010.03715.x

11. Talib Z, Kiguli-Malwadde E, Wohltjen H, Derbew M, Mulla Y. Transforming health professions' education through in-country collaboration: Examining the consortia between African medical schools catalyzed by the medical education partnership initiative. Hum Resources Health 2014;13(1):1. https://doi.org/10.1186/1478-

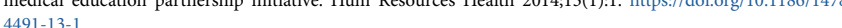

12. Chen C, Buch E, Wassermann T, et al. A survey of Sub-Saharan African medical schools. Hum Resources Health

13. Greysen SR, Dovlo D, Olapade-Olaopa EO, Jacobs M, Sewankambo N, Mullan F. Medical education in sub-Saharan Africa: A literature review. Med Educ 2011;45(10):973-986. https://doi.org/10.1111/j.1365-2923.2011.04039.

14. Zimbabwe National Statistics Agency. Census 2012 Report, Zimstat, Harare, Zimbabwe. 2013. www.zimstat. co.zw/ (accessed 26 July 2017)

15. Wilson NW, Couper ID, de Vries E, Reid S, Fish T, Marais BJ. A critical review of interventions to redress the inequitable distribution of healthcare professionals to rural and remote areas. Rural Remote Healt 2009;9(2):1060.

16. Strasser RP. Community engagement: A key to successful rural clinical education. Rural Remote Health 2010;10(1543):1-8.

17. Couper I, Hugo I, Conradie H, Mfenyana K. Influences on the choice of health professionals to practise in rura areas. S Afr Med J 2007;97(11):1082-1086.

18. Michaels D, Couper I. Guide for conducting peer reviews of community-based health sciences education programs: CapacityPlus. 2015. https://www.capacityplus.org/files/resources/cbe-peer-review-guide-final.pd (accessed 26 July 2017)

Accepted 5 March 2017 